International Journal of Linguistics, Literature and Translation

ISSN: 2617-0299 (Online); ISSN: 2708-0099 (Print)

DOI: 10.32996/ijltt

Journal Homepage: www.al-kindipublisher.com/index.php/ijltt

\title{
Rethinking the Insights from Good Language Learner Studies: Moroccan Learners of EFL as a Case Study
}

\author{
Bendaoud Nadif 18 (D) $\triangle$, Driss Benattabou 28 (D) \\ ${ }^{1}$ Ph. D. Student, English Department, Moulay Ismail University, Meknes, Morocco \\ 2 Professor, English Department, Moulay Ismail University, Meknes, Morocco \\ $\square$ Corresponding Author: Bendaoud Nadif, E-mail: bendaoudnadif@gmail.com
}

\author{
ARTICLE INFORMATION \\ Received: February 10, 2021 \\ Accepted: March 08, 2021 \\ Volume: 4 \\ Issue: 3 \\ DOI: $10.32996 /$ ijllt.2021.4.3.7
}

\section{KEYWORDS}

achievement, good language learners' characteristics, language learning strategies, learning styles.

\section{ABSTRACT}

Over the recent decades, there has been a growing research interest in placing learners at the heart of any enterprise pertaining to foreign language learning and teaching. Alongside the growth of new perspectives and theories in cognitive psychology and foreign language learning and teaching, research has shifted its focus from the teacher and learning outcomes to the learners and the learning processes. Correspondingly, researchers emphasize the significance of making the learning and teaching paradigms more supportive and responsive to learners' needs and interests to fully play more active and participatory roles. Drawing on researchers' contributions in the area of good language learner studies, this paper sets out to examine the relationship between the characteristics of GLLs and language achievement. For this purpose, a sample of $(\mathrm{N}=98)$ senior Moroccan high school students took an EFL achievement test and responded to the GLL questionnaire as designed and developed by Constantinides (2013). Using a Spearman correlational coefficient test and regression analysis, results show that GLLs' scores significantly correlate $(r=.81)$ and reliably predict the respondents' achievement test scores. The paper ends with a conclusion and some pedagogical implications to promote EFL learning and teaching.

\section{Introduction}

Research in the area of good and successful language learners (Rubin, 1975; Naiman et al., 1978; Stern, 1983; Lightbown \& Spada, 1993; Ellis, 1994) has been primarily concerned with the exploration and the identification of a host of qualities characterizing GLLs. Prior research focusing on the characteristics of GLLs seems to suggest that GLLs tend to display an array of traits and strategies that they employ to successfully learn the second/foreign language, and thus confirm that further studies on their characteristics may unavoidably foster the understanding of the subtle processes of language learning, and may help practitioners come into grips with the essence of how to assist less successful learners.

There is an implicit assumption here that once less successful learners are made fully aware and cognizant of these 'neglected strategies and skills', they may surely find themselves being placed on the right track conducive to more successful learning outcomes. This article revisits the question of the characteristics of the GLLs of English as a foreign language in secondary education in the Moroccan context. The research questions to be considered here are:

1) Are there any differences between students regarding their scores on the GLL index as designed and formulated by Marisa Constantinides (2013)?

2) Do students who display high scores on this GLL index also get good academic scores?

If this correlation is well-established, then this will undoubtedly confirm that it is these characteristics shaping the profile of GLLs which may have surely made the difference in achievement levels among successful and less successful language learners.

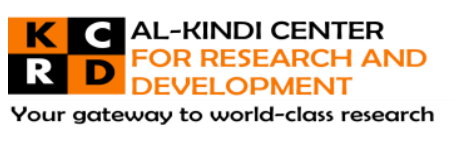

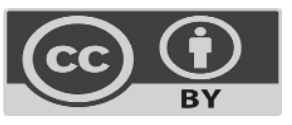

Published by Al-Kindi Center for Research and Development. Copyright (c) the author(s). This open access article is distributed under a Creative Commons Attribution (CC-BY) 4.0 license 


\section{Basic Theoretical Issues}

\subsection{Overview}

Throughout recent decades, research on GLLs has sparked considerable interest and debate in language learning and teaching in general and GLLs' characteristics and strategies in particular. In parallel with the development of new perspectives and theories both in cognitive psychology and second/foreign language learning and teaching, research has shifted its focus from the teacher and learning outcomes to the learners and the learning process. In this respect, Bruner (1960, p. 52) emphasizes the "need to learn how to learn". This shift to learner-centered education reflects a desire to explore ways of making the learning and teaching paradigm more enjoyable and in complete congruence with learners' needs and interests. In this respect, Rogers (1969) and Vygotsky (1978) contend that the most effective tools to prepare learners to cope with the new demands of this globalized age of the 'dot-com' is to foster their critical thinking, develop their learning autonomy and make them fully responsible for their own learning strategies and outcomes.

Language researchers accentuate the significance of foreign language learners' individual differences as they are seen to vary in substantial ways both in their different routes of learning as well as in their learning outcomes (Cohen \& Macaro, 2007; Grenfell, 2007; Macaro, 2006). Cohen and Dörnyei (2002) seem more inclined to contend that students learn in different ways to the extent that what works well for one learner might not work adequately well for another. White (2008) explains this shift in researchers' interests from teacher-centered approaches to learner-centered ones addressing new research paradigms which "focus on the learner, with growing inquiry into how language learners process, store, retrieve and use TL material" (p. 8). Brown (2007, p. 40) elaborates more on the issue arguing that it is necessary "to get on with the business of unifying our approach to language teaching and designing effective tasks and techniques that were informed by that approach."

What follows from this is that there is no 'best method' of language teaching; instead, the alternative is the eclectic approach/method (Prabhu, 1990; Kumaravadivelu, 1994). This implies that a variety of methods and approaches should be implemented, and the teaching methods are not the purposes, but the means of promoting the learning processes.

Past research on learning strategies focused on the good language learner. There is a general consensus among researchers (Naiman et al., 1975; Rubin \& Thompson, 1982; Green \& Oxford, 1995; Oxford \& Nyikos, 1989; Griffiths \& Pratt, 2001; Cohen, 2003; Dörnyei, 2005; Macaro, 2006) that good language learners tend to employ a wide range of effective language learning strategies to learn successfully. Other researchers tend to focus on promoting learner autonomy (Wenden \& Rubin, 1987).

Another stream of research seems more inclined to focus on the extent to which individual learners' variables may affect the differential achievement levels in language learning (Oxford, 2003; Dörnyei, 2005; Ellis, 2008; Skehan, 1991). In line with these variables, the language learning strategies (LLS) that learners deploy are also vital in promoting language learning. The research literature germane to good language learning strategies (GLLS) highlights the important and meaningful roles of such strategies in the academic achievement of language learners.

It is important to note that research on GLLs is central for (1) learners since it will increase their awareness of what adequate strategies to use in different learning contexts and tasks. Implications from this research can also support and reinforce less successful learners to adopt and utilize such effective strategies to enhance and facilitate the learning process ; (2) teachers can develop a well-informed insight into accommodating their teaching approaches and practices to learners' needs and strategy use ; and (3) curriculum and material developers could adopt the contents and methodologies that cater for different learners' needs, bearing in mind their mixed and differentiated abilities, learning styles, characteristics as well as the most frequently used strategies.

In this respect, raising consciousness about the importance of GLLs' characteristics could be conducive to conscious learning as learners will reinforce strategy use along their learning process. In line with this, teachers could reconsider their teaching practices and adjust their roles to suit the learners' needs in the classroom environment and elsewhere. O'Malley \& Chamot (1990) and Oxford \& Cohen (1992) stress that the more conscious learners are of the strategies they use, the more effective and skillful they will become. Oxford (1990, p. 8) divides learning strategies into six types: (1) memory strategies, (2) cognitive strategies, (3) compensation strategies, (4) meta-cognitive strategies, (5) affective strategies and (6) social strategies. The implication that can be drawn from this definition is that strategy refers to learners as active and autonomous agents taking up conscious actions and objectives. 
Following the same line of reasoning, Chamot (2005) aptly contends that:

The study of language learning strategies will continue to develop as second language acquisition researchers seek to understand different learner characteristics and the complex cognitive, social, and affective processes involved in processing language input and using the language for a variety of purposes. (p. 126)

The corollary of this is that the current findings are just the apparent part of the iceberg and further research is still needed to develop a better understanding of different variables related to language learning in general and strategy use in particular. Wahyudi (2014, p. 4) reports, in this respect, that L2 learners could be assisted to enhance their language proficiency levels through developing their awareness of how to use the appropriate language learning strategies.

As a matter of fact, good language learning strategies could presumably assist less successful language learners who can be taught new strategies that would help them become independent and better language learners (Chamot, 2005, p. 112). Further research on language learning stresses that, no matter how similar the approaches, the materials, the contexts and learning/exposure time span might be, foreign language learners tend to vary both in their learning strategies and their language achievement levels. Brown (2006) and Richard \& Roger (2014) argue that there are significant differences in second/foreign language learners' achievement and performance. There are highly successful language learners and less successful ones in easy terms. Rubin (1975, p. 41) poses a critical question that "if all people can learn their L1 easily and well, why does innate ability seem to decline for some when L2 learning is the task?"

\subsection{Characteristics of Good Language Learners}

One of the first research inquiries focusing on good language learners' characteristics was developed by Rubin (1975). This was undertaken in one of Rubin's most often-cited article: "What the 'good language learner' can teach us". Based on her longitudinal study, Rubin (1975, p. 42) claims that aptitude, motivation and opportunity are the three predominant variables that successful learning depends on. Although there are many classifications for language learning strategies (LLS), the majority of these classifications reflect ample similarities in categorizing LLS without fundamental differences. Bialystok (1978, pp. 69-83) suggests a model for LLS that comprises (a) functional practicing, (b) formal practicing (c) monitoring, and (d) inferencing. Rubin (1981) puts forward a classification of strategies used by successful language learners, namely direct and indirect cognitive strategies. Based on Rubin's model, direct strategies are specific actions that contribute to the learning process and include (1) clarification and verification, (2) monitoring, (3) memorization, (4) guessing/inductive inferencing, (5) deductive reasoning, and (6) practice. Indirect strategies are actions that assist learning but not contribute directly to learning, encompassing opportunity for practice and production tasks associated with communication, motivation and exposure to language.

Rubin (1975, p. 49) attributes this differential success among good language learners themselves to the (a) the tasks, (b) the learning stage, (c) the learners' age, (d) the context, (e) individual styles, and (f) cultural differences in cognitive learning styles. These differences might be attributable to the ways and degrees of effectiveness in using language learning strategies as well. Moreover, Gardner (1975) and Hatch et al. (1976) underline six principal concepts in language learning: (1) context, (2) learner, (3) L2 teaching, (4) L2 environment, (5) learning, and (6) outcome. Accordingly, taking into account the different variables that promote or impede effective language learning, the levels of proficiency range from low or slow achievement to native-like mastery.

Regarding the variable of age, language researchers' views vary as to what is the most optimum age of learning a second or foreign language. For instance, Rubin \& Thompson (1994, pp. 4-8) lay more stress on the fact that age has its advantages and disadvantages in the process of second language learning. The advantages of young age are the ability of children to learn easily, to pursue language study over longer periods of time and to pick up an authentic accent. Adult learners also have better strategies, prior experience, better memories, more efficient ways of organizing information, longer attention spans, better study habits and greater ability to handle complex mental tasks. Additionally, they are often more motivated than children not only because adults see language as necessary for their education or career, but also because they are sensitive to the accuracy of grammar and the appropriateness of vocabulary.

However, age has its drawbacks as well. Although children devote many years to language mastery, they have fewer opportunities to practice language. Unlike children, adults want to learn a foreign language in a hurry because they have complex communication needs that extend beyond the mere ability to engage in simple conversations. In fact, adults need to argue, persuade, express concern, agree/disagree, explain and present information about complex matters that pertain to their life, interests, work, or education. Since most adults cannot tolerate appearing foolish, they often deny themselves opportunities 
to practice L2 for fear of making mistakes, not getting their messages across, or seeming ridiculously incompetent, especially when they are learning with younger learners in the same learning context.

In the same respect, Falk (1978, p. 56) suggests that the language learning capacity may be more difficult to activate among adults, but it is not lost. Although several research studies have been carried out into adult and child second language learning in support of both sides of this controversy, the majority of researchers (e.g. Snow \& Hoefnagel-Hohle, 1978; Benattabou, 1990) seem to have consensus that 'the younger is better' for L2 learning.

One study which contradicts the 'younger is better' view was conducted by Walburg in 1978. He studied the language proficiency of children of Japanese business working in the United States of America. Rather than supporting the idea that younger learners are superior language learners, Walburg (1978) concluded that language proficiency was related to the amount of time spent in the L2 learning context and not the age of arrival. Summarizing mainstream research on the significance of age in second/foreign language learning, Krashen et al. (1979, p. 573) put it succinctly that "the available literature is consistent with three generalizations concerning the relationship between age, rate, and eventual attainment in L2 acquisition/learning."

Note shall be made here that questions of the relationship of age to $L 2$ learning remain still unresolved given that the majority of the studies that have been conducted up to this point have been short-term. Therefore, more long-term studies need to be undertaken in this research area in order to determine the potential rapports of the age factor to language acquisition/learning.

The second variable related to successful language learning is motivation. Commonly, motivation refers to the spur that drives language learners to boost their language in terms of knowledge, skills and attitudes. Gardner \& Lambert (1972, p. 135) suggest another approach, namely the socio-psychological model whereby the good language learner is supposed to socialize with the native speakers of the target language and know more and more about their culture. Gardner \& Lambert (1972) contend that the attitudes of language learners towards the culture of the target language and its community have a fundamental impact on their motivation as well as their achievement in learning.

Gardner and Lambert's model brought about two types of motivation: integrative and instrumental motivations. Integrative motivation stems from personal interest in the target language, its people and culture. In contrast, instrumental motivation reflects the practical, beneficial and material values and advantages of learning L2, such as having better job prospects and opportunities, or using L2 in higher education research. Gardner (1988) provides a new approach that of the socio-educational model. Despite Gardner's transition from the socio-psychological model of language learning to the socio-educational one, his theory and the research elicited thereby received much criticism due to its failure to adequately consider the classroom context of learner motivation (Crookes \& Schmidt, 1991, p 41). In this regard, Ushioda (1996) posits that such failure may be a reflection of the discrepancies among the concerns of researchers and teachers. Therefore, Crookes \& Schmidt (1991) called for a more practitioner-oriented classroom-based concept of motivation.

The 1990s marked an unprecedented research interest among motivation scholars. Gardner \& Tremblay (1994, p. 526) referred to that decade as 'motivational renaissance' or awakening. Dörnyei (2001, pp. 103-105) highlights the relevance of more 'education-friendly' approaches to language learner motivation in the sense that it contributes to deeper and better insights for both teachers and learners. Deci \& Flaste (1996, p. 10) underscore the crucial relevance of learners' internal motivation 'motivation from within'. Thus, the optimal kind of motivation from within is identified as 'intrinsic motivation', i.e., learning language for its sake, for interest, love, challenge, skill, knowledge development and similar enjoyable rewards.

Unlike intrinsic motivation, extrinsic motivation is related to learning language as a means to some separable outcomes, such as obtaining a certificate / a qualification, getting a job, being promoted, satisfying the parents / the teachers, or avoiding punishment (Ryan \& Deci, 2000, pp. 54-67). There is noticeable body of research in favor of intrinsic motivation since it promotes spontaneous learning behavior advantageously. Nevertheless, extrinsic motivation should not be overlooked nor dismissed. What is more critical is not whether motivational factors are intrinsic or extrinsic to the learning process, but whether they are internalized and self-determined, or externally imposed and regulated by others, including but not limited to teachers, peers, curricula, parents, educational, and societal expectations (Norton \& Toohey, 2001, pp. 307-322).

Regarding the social context motivation model, there has been increasing concern among motivation researchers (Mclnerney \& VanEtten, 2004; Volet \& Järvelä, 2001) in the socially situated context of motivation, and in the pivotal aspects and roles of social processes and influences in shaping individual motivation. Accordingly, surveys in education addressed a set of determinant 
situational factors, basically societal and cultural influences, curricular and institutional context, classroom environment, peer relations, teaching styles and methods, materials and task design.

Additionally, Dörnyei's (1994, pp. 273-283) framework of motivation represents a combination of 'language- associated' and 'learner-internal' factors with learning situation factors, along with teacher socialization of motivation and classroom group. Vygotsky (1978) posits that the socio-cultural theory of the mind is the principle as "higher-order" cognitive functions are internalized from social interaction with other more subtle socio-cultural factors. Similarly, Bronson (2000, p. 25) emphasizes that "thinking, wanting and doing are shared and jointly constructed in the dialogic interactions between learners and members of the surrounding culture or social learning environment".

Likewise, Norton \& Toohey (2001, p. 310) point out the limitations of putting emphasis only on "the mental processes, and on the influence of 'good' language learner characteristics upon such processes". Accordingly, Norton \& Toohey entail the need for a dual focus on GLLs and on the social practices in the language learning contexts.

Another variable is aptitude. A learner's aptitude reflects strengths and weaknesses in a range of cognitive abilities that underlie the process of language development. Aptitude interacts with other variables such as motivation and opportunity. Carroll's (1981) model of aptitude consists of four components: phonetic coding ability, rote memory, and the ability to carry out grammatical analysis. Robinson $(2001,2002)$ has re-conceptualized the components of aptitude into a hierarchical arrangement of aptitude variables that jointly influence learning. Skehan $(1998,2002)$ has advocated the use of compensatory instruction rather than matching individualized instruction for aptitudinal weaknesses because the components of aptitude relate to specific stages in the acquisition/learning process.

Griffiths (2008, p. 143) recommends that "teachers committed to the principle of learner-centeredness should (...) address not only the real-life goals and learning preferences of students but also their cognitive processing needs". It is conceivably a daunting expectation. Nevertheless, accommodating the aptitude profiles of their learners is one way that teachers can take into account in their teaching practices that will help their students become the best language learners they can be.

There is also evidence from research demonstrating that the prerequisites of favorable and supportive language learning environment are (a) learner engaging classroom activities in which learners fully participate actively and interactively ; (b) ensuring opportunities for realistic communication whenever possible; (c) creating opportunities for learners to do selfcorrection and respond to feedback on their performance and the performance of their peers ; (d) encouraging learners to take risks in their learning endeavor so that they could feel secure when they make mistakes; (e) maintaining a supportive and nonthreatening learning environment to support every learner to cope with the tasks ; and ( $f$ ) a sense of understanding the system in which a particular language functions (Griffiths 2008, p. 145). The aforementioned prerequisites are likely to maximize the options for different learners.

Rubin (1975, p. 42) identifies the characteristics of good language learners as (1) being willing and accurate guesser; (2) willing to communicate; (3) often not inhibited; (4) they learn to live with uncertainty (they tolerate ambiguity and vagueness); (5) able to attend to forms and patterns. Thus, they use the prior linguistic knowledge actively, including the knowledge of their L1 in mastering a second/foreign language; (6) able to create and seek out opportunity to practice and use language; (7) able to monitor their own speech performance; (8) they make errors work positively; (9) able to pay attention to the meaning and the context of speech. They also make use of the context; (10) they develop strategies for making sense of the target language without worrying about understanding the meaning of every single word ; (11) they learn connected items or phrases 'chunks' of language as wholes and formalized routines to sustain learning and effective performance that can go beyond their competence; (12) they learn different styles of speech and writing and learn to vary their language according to formality/informality degrees of the situation; and (13) they learn production techniques. It is clear that such traits are indispensable for successful language learning, though they might not be attainable for every GLL. In a similar vein, Stern (1975, p. 311) lists the top ten characteristics of GLLs that relate to the aforementioned ones.

Regardless of the learning environment conditions, some learners manage to be outstandingly successful. Indeed, research studies carried out by O'Malley \& Chamot (1990, p. 44) point out that good language learners are characterized by being flexible and willing to vary their learning strategies, i.e., these learners are not tied to one specific set of options. Stated differently, GLLs adopt, change, and try new and various learning approaches to different learning experiences, contexts and mindsets. GLLs take charge of their learning. They are also physically and mentally organized. They are creative and innovative. In addition, they think critically and do their best to practice language inside the classroom and elsewhere. Besides, they are willing to learn and bear 
making mistakes. Equally important, they seek opportunities to use language genuinely or through simulations. GLLs focus more on fluency and meaning rather than accuracy. Additionally, they use memory strategies such as mind graphs, semantic mapping, charts, flashcards, songs, films, riddles, tongue twisters, and other mnemonic devices.

\section{Research Methodology}

\subsection{Research Questions}

This study sets out to answer the following two research questions:

1) Are there any differences between students regarding their scores on the GLL index as designed and formulated by Marisa Constantinides (2013)?

2) Do students who display high scores on this GLL index get also good academic scores?

The null hypothesis: there is no correlation between GLLs score and academic achievement. The alternative hypothesis: there is a correlation between GLLs' scores and academic performance.

\subsection{Participants}

The target population was represented in our study using a non-probability convenience sample. This sampling procedure resulted in the selection of a group of ninety-eight $(N=98)$ senior public high school second year Baccalaureate students, of which 46 were males with a percentage of (47\%) and 52 were females averaging a percentage of (53\%). They were all enrolled in Lycée Ezzerktouni, a public high school which is located in the region of Beni-Mellal in Morocco. The subjects of this study seemed to share a number of traits in common as they were all exposed to the same teaching materials, taught by the same teachers, and being subject to the same teaching and learning conditions.

With a mean of 11.98 , the highest reading comprehension score obtained was $19 / 20$ and the lowest was $6 / 20$. The minimum age was 17 and the maximum age was 20 .

The participants completed the GLL questionnaire as designed and formulated by Constantinides (2013). Some of the items in the original version of this questionnaire have been deleted and others have been included to serve the particular purposes of this study. These students have also been evaluated based on their scores on a reading comprehension test. The students spanned over multiple classes, and their high school teachers supervised both the completion of the questionnaires and the testing operation resulting in the compilation of our convenience sample. The data were processed using SPSS (Version 23) and Microsoft Office Excel (Version 2007).

\subsection{Instruments}

\subsection{GLL questionnaire}

Drawing on the results and the implications of a number of good language learner studies (Rubin, 1975; Stern, 1975; Wenden \& Rubin, 1987), Constantinides (2013) developed and put forward the Good Language Learners characteristics questionnaire to assess students' use and manipulation of a number of GLL traits. For convenience and for the purposes of the current study, we adapted Constantinides' questionnaire items to the local context by deleting some items and substituting them with more context-specific ones to make them suit the Moroccan social context.

The questionnaire aimed at investigating the GLLs traits in the Moroccan secondary educational setting. The items that this questionnaire consists of purported to assess a host of characteristics pertaining to the profile of "the Good Language Learner" as is thought of and described by most of "the Good Language Learner studies" surveyed and outlined in the review of the literature. It encompasses 21 yes-no questions with each question translated into a categorical dichotomous variable. For instance, items 1 and 12 deal with individual factors namely preferred learning styles. Items 18 and 20 respectively attempt to explore the respondents' attitudes towards the English language and culture. Items 2 and 3 investigate anxiety and selfconfidence. Furthermore, items 6, 7, 9, 14 and 21 deal with meta-cognitive factors such as strategic awareness as well as language and culture awareness. Item 17 is about socio-affective factors like readiness to adapt to the new learning environment. Item 4 and 5 target self-efficacy, organization and intensive effort to learn and acquire the language.

In this respect, the questionnaire includes multiple qualifications and preferences which can be identified using the participant's choices (e.g. language use risk-taking, language-experimenting asking respectively: Are you? a. Prepared to take risks or b. Do you avoid risks and prefer to be safe? And, Do you prefer to a. Experiment with language or $b$. Repeat only sentences you were taught?). The aggregate GLL score is calculated by summing up item responses. The results range between 00/21 and $21 / 21$. 


\subsubsection{Academic achievement test}

The reading comprehension test is a standard composite made up of elements comprising a number of skills, namely a text with reading comprehension questions, language, functions and writing adopted from the 2018 Baccalaureate examination pack issued by the National Center of Exams of the Ministry of Education in Morocco. The exam score ranges between the minimum of 0 and the maximum of 20 .

In order to examine the relationship between the variable of GLLs' characteristics and language learning, an achievement test of English was administered to these students at the end of the first semester during the academic year 2019-2020. The learners' language performance was assessed by means of three sub-skills.

The items were designed to assess different skills in English. The different levels that the subtests purported to measure were planned on the basis of their relevance to the learners' level of study, to what was being taught in class and its relevance to EFL learning in the Moroccan secondary education system. This implies that attempts have been made to evolve within the framework outlined by educationalists to draw the basic requirements of an achievement test (Tuckman, 1975)

The English achievement test comprises three tasks. The first sub-skill pertains to the reading comprehension course. A 500word passage in English supplemented by a variety of questions was constructed. The text was followed by three Wh-questions that assess the learners' broader understanding of the reading comprehension text. Then, 'true or false' questions were used to measure the learners' specific understanding of the reading comprehension text. The third comprehension task seeks to evaluate students' ability to understand English and paraphrase different sentences from the text. This was followed by two questions that require the learners to complete two sentences based on the content of the text. Students were also required to provide three synonyms for the given words from the text. The last comprehension question targeted word reference.

The second subtest is meant to assess students' mastery of the grammar content. Five items were introduced in this respect to measure the following: (1) accuracy in the use of tenses; (2) accuracy in handling the appropriate use of modals; (3) accuracy in exploiting correct grammatical structures related to the use of the passive voice; (4) selecting the right affixes; (5) accuracy in handling reported speech structures, and (6) functions.

The third and last battery was related to the writing skill which comprises two tasks. Both tasks were included in the battery mainly because of their integrative nature in measuring a number of objectives at the same time such as the relevance of the content to the topic of the tasks, appropriateness and variety of vocabulary items, grammar accuracy and the right use of mechanics. In the first task, students were required to complete a paragraph that begins with a topic sentence and has some linking words. In the second task, students were demanded to write a one-paragraph essay which satisfies the requirements of a good composition, including the use of an appropriate topic sentence backed up by at least three supporting sentences and a concluding sentence. Students were asked to pay meticulous attention to the mechanics of writing including indentation, capitalization, and punctuation.

The GLL Score ranges between 0/21 and 21/21 according to the number of items that the respondents select to generate a total score. Following Marisa Constantinides' (2013) conception of the questionnaire, if the total score is $70 \%$ and above the rate of GLL total score, the respondents possess the attributes of GLLs.

\section{Results}

By examining numerically and statistically our database through SPSS, results revealed no missing data points for all the records. Table 1.1 shows a description of the sample; Table 1.2 displays both the results of the achievement test scores, and the Good Language Learners scores.

Table1.1. Descriptive Statistics of the Students Sample ( $N=98)$

\begin{tabular}{lllll}
\hline Gender & Frequency & Percent & Valid Percent & Cumulative Percent \\
\hline Males & 46 & 46,9 & 46,9 & 46,9 \\
Females & 52 & 53,1 & 53,1 & 100,0 \\
Total & 98 & 100,0 & 100,0 & \\
\hline
\end{tabular}


As can be gleaned from the table above, the gender of the respondents who participated in this study indicates that there are 52 $\%$ female students and $46 \%$ male students. It is obvious that the percentage of females is slightly higher than males.

In order to measure the strength of the correlation between GLL score and the achievement test score, we opted for the nonparametric Spearman correlational coefficient. The results (Table 1.2) show a very strong positive correlation $r(98)=.81, p=.001$ between the two variables.

Table 1.2. Pearson Correlational Analysis between GLL Score and Achievement Test Score $(N=98)$

\begin{tabular}{ll|l|l} 
& & GLL_score & Achievement Test_score \\
\hline GLL_score & Pearson Correlation & 1 &, $812^{* *}$ \\
\cline { 2 - 4 } & Sig. (2-tailed) & 0 \\
\hline & $\mathrm{N}$ & 98 & 98 \\
\hline Achievement Test_score & Pearson Correlation &, $812^{* *}$ & 1 \\
\cline { 2 - 4 } & Sig. (2-tailed) & 0 & \\
\hline & $\mathrm{N}$ & 98 & 98 \\
\hline
\end{tabular}

**. Correlation is significant at the 0.01 level (2-tailed).

In the same manner, the scatter plot (Figure 1) shows graphically that the various data points associated with GLL scores are aligned in such a coherent and clustered fashion that the regression line seems to fit well in the data cloud.

Figure 1GLL Score ( $X$ axis) and Achievement Test Score ( $Y$ axis)

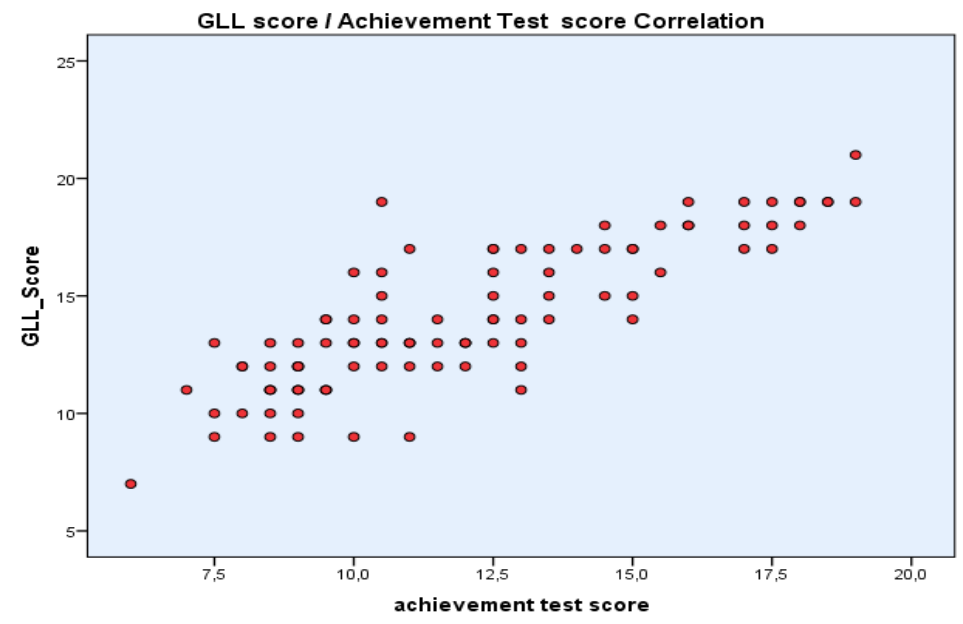

As Figure 1 indicates, the slope in the scatter plot forms a linear positive correlation. The majority of points fall along the line and are close together clustered in the same region. In other words, there is a high concentration of the points along the line. There are also a few outliers towards the bottom of the line. To illustrate this, the slope of the GLL lowest score is $7 / 21$, and the lowest achievement Test score that corresponds to it is $06 / 20$. However, one point that does not fit the pattern is apparent in the slope $\mathrm{GLL}=19$ / Achievement Test=10.5. 
In addition to correlation analysis and using simple linear regression, results show that approximately seventy eight percent $(81 \%) R^{2}=81, F(1,96)=350.170, p<.001$ of the variability in the achievement test score is explained by the GLL score. It appears clearly that GLL scores predict significantly $\beta=88, t=13.61, p<.001$ (Table 1.3) the achievement test score.

Table 1.3. Regression Analysis Summary for GLL Score Predicting the Achievement Test Score $(N=98)$

\begin{tabular}{lllll}
\hline Variables & $\mathrm{B}$ & $B$ & $\mathrm{t}$ & $\mathrm{P}$ \\
\hline (Constant) & .234 & - & .264 & .000 \\
GLL score & .88 & .81 & 13.613 & .000 \\
\hline
\end{tabular}

Note. $R^{2}$ adjusted $=.81$

Regarding the choice of the questionnaire items, the data demonstrate that the percentage of respondents who answered 'yes' is significantly higher than those who opted for 'no'. This means that the respondents who chose the 'yes' option have more positive effective language learning traits compared to those who opted for 'no'. The latter category of students lacks the positive qualities of good language learners. In this respect, the respondents who are likely to possess the good language learning characteristics represent $67 \%$ of the total percentage of the sample investigated in the present study.

The pie-chart in Figure 2 highlights the respondents' scores in the achievement test distribution which ranges between 00/209.5/20 and 10/20-20/20. The apportionment reveals that 68 respondents from the sample scored between 10/20 and 20/20, whereas 30 respondents scored below 10/20.

Figure 2. The proportions of Achievement Test Scores

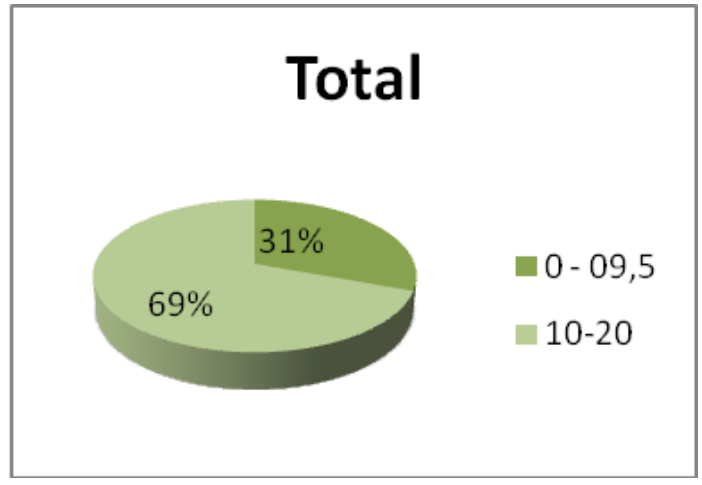

Figure 3. The proportions of GLLs Scores

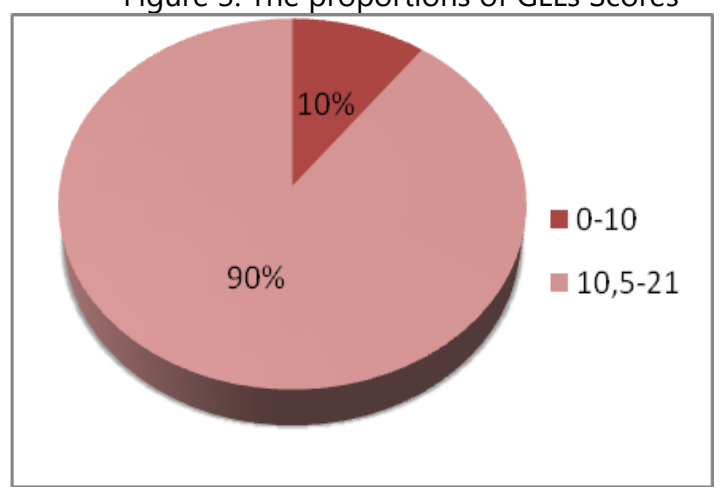

The pie-chart in Figure 3 highlights the respondents' scores in the GLL distribution which ranges between 00/21-10/21 and $10.5 / 21-20 / 21$. The apportionment reveals that $90 \%$ of the sample scored approximately between $10.5 / 21$ and up to $20 / 21$, whereas $10 \%$ scored roughly under $10.5 / 21$. Therefore, the pie-chart crucially suggests that the larger proportion of the sample received high scores in the GLL index.

According to Marisa Constantinides' index, the respondents who get the score of $70 \%$ and above of the total could be classified as holding higher GLL score. When we applied this measurement to our sample, as the results in Figure 5 indicate, the number of GLL high-achievers outnumbered the GLL low-achievers. Thus, the rate of high-achievers among the GLLs of this sample is approximately twice higher. Similarly, Figure 2 confirms that the results follow the same pattern, i.e., the high-achievers in the achievement test outnumbered the low-achievers over twice. 
Figure 4. GLL Score and Achievement Test Score

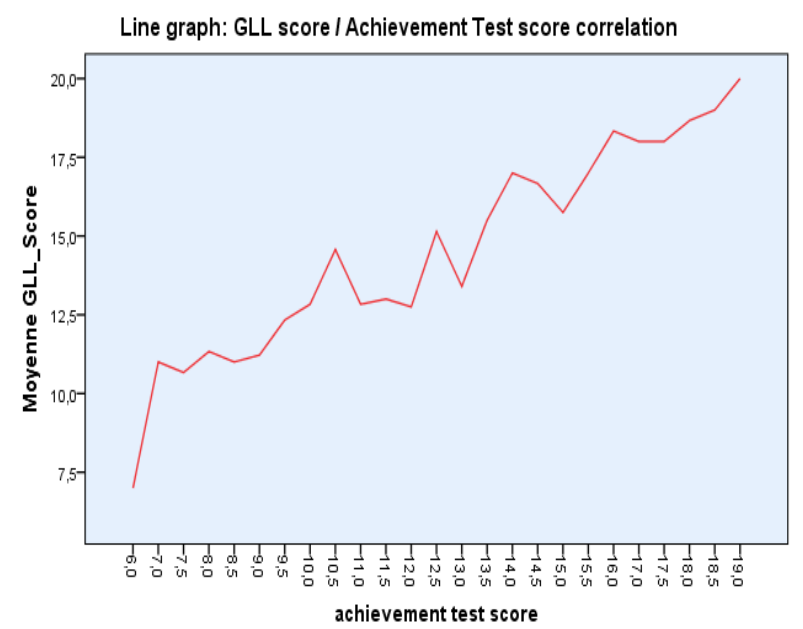

Figure 5. The Proportions of GLLs

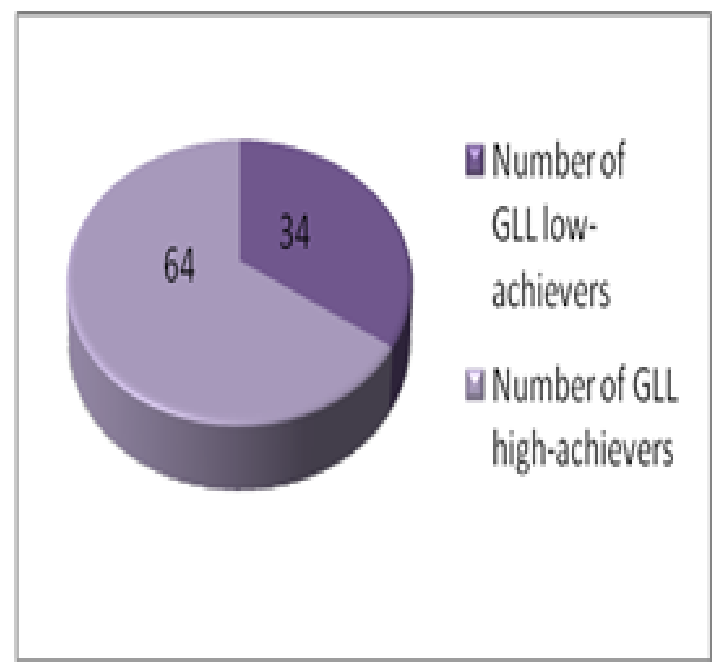

The line graph cited earlier (Figure 4) demonstrates the significant correlation between GLL scores and the achievement Test scores. Obviously, as the GLL scores increase, so do the achievement test scores.

\section{Discussion}

At first, data scanning was performed. The results did not show any missing data. Subsequent to this, a correlation analysis was conducted. The typology of the data dictated the choice of the correlational test. In this case, since there is one dichotomous variable with two levels on a nominal scale and a score variable on an interval variable, the literature points to Point-Biserial instead of Pearson for interval-interval or Spearman for rank-ordered types of data (Hatch \& Lazaraton, 1991). However, after having calculated the summed score of GLL characteristics, the results became assimilated to continuous data. This means that the data could be analyzed using Spearman correlational coefficient test if fundamental assumptions such as the normal distribution are violated (Hatch \& Lazaraton, 1991).

The statistical analysis shows that there is a positive correlation $r(98)=.88, p=.001$ (Table 1.3) linking GLL scores and the Achievement Test. One way to interpret this is that in the presence of multiple variables (e.g. empathy, mode of work preferred, and learning style) correlated individually with the achievement test scores, the sum total of cumulative correlation coefficients becomes much stronger the more correlations there are. This could be demonstrated through showing individual correlations of GLL items with the Achievement Test. However, given the complexity of processing each single correlation in relation to the achievement test score in isolation, GLLs were dealt with as a whole.

Another aspect is the positive part of the correlation. It should be said that this does not mean at all that the less characteristics learners have, the more likely they are to score lower in the achievement test; quite the contrary in fact as the answer demonstrates preference rather than superiority or the absence of a quality. This is best explained by an example. The question number 16 is about Risk-taking and this quality is identified through the question "Are you: Prepared to take risks or Do you avoid risks and prefer to be safe?" This item was found to correlate with achievement test score $r(98)=.26, p=.001$. This particular result can be interpreted by saying that the more students are risk-avert or avoid risk, the more likely they are to score higher in the achievement test.

Further, the findings displayed in Figures 3 and 5 fit with Constantinides' index. To back up this point, when we consider that the average of the GLL score is $10.5 / 21$, the proportion of GLL high-achievers rises to $90 \%$ as displayed in the chart above (Figure 3 ). Correspondingly, figure 5 indicates that the number of GLL high-achievers outstrips the GLL low-achievers. Thus, the rate of high-achievers in GLL score in this sample is approximately twice higher. In this regard, the findings tend to highlight the meaningful relationship between GLL score and academic achievement; the higher the scores of the GLLs questionnaire, the better the achievement test scores are delineating a positive correlation. 
Our main hypothesis stating that there is a correlation between GLL characteristics and the achievement test has been confirmed. This further confirms the long-standing conclusion that good language learners have characteristics that manifest themselves in terms of academic achievement and in our context, reading comprehension, grammar, functions and writing achievement.

Having shown that GLL scores and the achievement test scores are correlated, it follows statistically that one can predict the other since regression uses an underlying correlation coefficient to produce the regression equation. The results $\beta=88, t=13.61$, $p<.001$ (Table 1.3) show that GLL characteristics are a highly reliable predictor of the achievement test scores. This is by most statistical standards a major correlation representing a significant finding. The findings of this study seem to resonate well with other research studies substantiating the same correlation (Bialystok \& Fröhlich, 1978; Hansen \& Stansfield, 1981; Norton \& Toohey, 2001).

\section{Conclusion}

Ultimately, research into the characteristics and strategies of good language learners provides us with further evidence that successful language learners share a plethora of learning traits which make their learning easier, enjoyable and worthwhile. The purpose of this study is two-fold: first, it attempts to survey previous research through analyzing and identifying the underlying common traits shared by good language learners. Second, it corroborates the view that educationalists in general and educators in particular, will surely do a great disservice to less successful language learners if they continue to maintain a laissez-faire attitude towards them. It is; therefore, the responsibility of all stakeholders to make some daring steps ahead to conscientiously acquaint less successful learners with these 'lacking features' that will definitely assist them in their journey to learn second/foreign languages.

The findings of the study indicate that there is a significant correlation between GLLs' characteristics and academic achievement. This important finding regarding the link between the variables further confirms the hypothesis results thus reinforcing the research question from an additional perspective. It should be noted that the findings should in no way be generalizable as there is still a need for more large-scale studies, which include larger samples, in order to examine the relationship in detail. More indepth studies could provide a deeper insight into good language learning characteristics where the individual variables might be studied separately and reproduce these results in other similar contexts.

\subsection{Pedagogical Implications}

The implication here is that educators need to consider the characteristics of GLLs and the meta-cognitive strategies these learners tend to possess, use and exploit during their language learning journey. In parallel, educators could also transmit the GLLs' characteristics and strategies to those students who are lacking them. This is the main philosophy behind attempting to learn from good language learners. For an effective transfer and dissemination of GLLs characteristics to less successful learners, teachers should ensure a large range of approaches to cater for the learners' various needs and interests and different preferred styles. In this respect, research on good language learners' characteristics and their learning strategies would assist other learners through raising their awareness to the relevance of using effective strategies in the teaching/learning process. Similarly, teachers could give prominence to the strategies that learners might not employ "neglected strategies". Teachers would likewise reflect on the teaching practices, and adopt materials and activities that accommodate strategy use to the learning objectives. All sorts of good language learning characteristics and strategies are supportive and conducive to proactive learning, and hence lead learners to be more autonomous and self-directed. If students are cognizant of GLL traits and strategy use, they could be equipped with lifelong learning techniques that will guide them throughout their lives.

The classroom is an environment where students are exposed to constructive content, vocabulary items and grammar structures where language is progressively built and can be used both individually and collectively in a relatively free and controlled setting. Nevertheless, grammar and vocabulary are not all since other important if not more important assets that teachers can deliver to students are efficient meta-cognitive strategies in the process of language learning and teaching. The teacher by definition plays a very instrumental role in facilitating the process of learning and transfer of the best language learning traits and strategies that GLLs use in their own learning to the low-achievers, thus paving the way for autonomous learning.

A further practical implication for EFL teachers is to incorporate the characteristics of GLLs as well as adequate strategy training in the classroom. Put differently, training learners on how to use effectively language learning strategies that are used by GLLs may surely help promote their language learning outcomes. To sum up, it is highly recommended that teachers take into consideration the characteristics of GLLs and language learning strategies in lesson planning in order to (1) cater for the needs of different learners, (2) facilitate and maximize learning in classes, particularly in settings where there are learners with mixed 
abilities, (3) get learners to reflect on the learning processes and experiences, (4) support learners to enhance their selfawareness, and (5) enable them to increase their learning opportunities via using all the digital devices that are available.

Additionally, it is also recommended that researchers and practitioners carry out more surveys in order to have an in-depth understanding of the characteristics of GLLs, how and what good language learners do to acquire/learn English. Therefore, passing on these traits and strategies to other learners to help them learn in more efficient ways "learning how to learn" will be of paramount importance to enhance their autonomy. Another implication is that the implementation of GLLs in the curricula and in the classroom could minimize the differences that prevail between good learners and less effective ones, especially in mixed ability classes as is the case with the Moroccan context. It is worth noting that good language learners' behaviors need to be operationalized if they are to be of use to language learners and teachers. For example, language practices need to be linked to meaningful instances of personal language use that relates to learners' real lives in order to make the learning journey beneficial and more rewarding.

As a matter of fact, the most common characteristics of good language learners can be summarized in the fact that (1) they are curious, which means that they are keen on the discovery part of learning ; (2) they think about how they learn and wonder about all sorts of matters, often about aspects beyond their area of expertise; (3) they are willing to experiment and take risks 'uninhibited'; (4) they are realistic ; (5) they are independent: they realize that they hold responsibility of learning, turning in assignments and preparing for the examinations; (6) they are committed to learning; (7) they are persistent; (8) they have concern for communication and care much more about fluency than accuracy ; (9) they use a number of strategies; (10) and they use top-down and bottom-up processes. They pursue understanding diligently. They talk with others, read and study more and more. Finally, good language learners are process-oriented as they focus much on how to become better learners, rather than of the end results.

Thus, it is of paramount importance that language learners need to have access to the aforementioned characteristics that may surely enable them to become more effective and more efficient learners. They will be able not only to adapt but also to thrive in a changing world, particularly in this age of the dot-com where "thinking, pairing, and sharing "via social-media is providing much more input and much more exposure to language use.

Funding: This research received no external funding.

Acknowledgments: I would like to thank the participants and my supervisor for their support.

Conflicts of Interest: The authors declare no conflict of interest.

\section{References}

[1] Benattabou, D. (1990). The significance of the factors of age and sex in the learning of a second language. A case study of Moroccan learners. [Unpublished D.E.S paper], Faculty of letters. Sidi Mohamed Ben Abdellah University, Fez.

[2] Bialystok, E. (1978). A theoretical model of second language learning. Language Learning, 28, 69-83.

[3] Bialystok, E., \& Fröhlich, M. (1978). Variables of classroom achievement in second language learning. The Modern Language Journal, 62(7), 327-336.

[4] Bronson, M. (2000). Self-regulation in early childhood: Nature and nurture. Guilford

[5] Brown, H. D. (2007). Teaching by principles: An interactive approach to language pedagogy (3rd Ed.). Pearson Education.

[6] Bruner, J. S. (1960). The process of education. Harvard University Press.

[7] Carroll, J. B. (1981). Twenty-five years of research on foreign language aptitude. Individual differences and universals in language learning aptitude, 83(117), 867-873.

[8] Chamot, A. U., Barnhardt, S., El-Dinary, P. B., \& Robbins, J. (1999). The learning strategies handbook. Addison Wesley, Longman.

[9] Chamot, A. U. (2005). Language learning strategy instruction: Current issues and research. Annual Review of Applied Linguistics, 25, 112130.

[10] Cohen, A., \& Macaro, E. (2007). Language learning strategies: Thirty years of research and practice. Oxford University Press.

[11] Constantinides, M (2013, November 7). Are you a good language learner?. Retrieved from https://celtathens.com/2013/11/07/are-you-agood-language-learner/

[12] Dörnyei, Z. (1994). Motivation and motivating in the foreign language classroom. Modern Language Journal, 78, $273-284$.

[13] Dörnyei, Z. (2001). Teaching and researching motivation. Longman.

[14] Dörnyei, Z. (2005). The psychology of the language learner. Lawrence Erlbaum Associates.

[15] Ellis, R. (1994). A theory of instructed second language acquisition. Implicit and explicit learning of languages, 726.

[16] Ellis, R. (2008). The Study of second language acquisition. Oxford University Press.

[17] Falk, J. (1978). Linguistics and language: A survey of basic concepts and implications. John Wiley and Sons.

[18] Gardner, R. et al. (1997). Towards a full model of second language learning: An empirical investigation. The Modern Language Journal, 81, 344-362.

[19] Green, J., \& Oxford, R. (1995). A closer look at learning strategies, L2 proficiency, and gender. TESOL Quarterly, 29, $261-297$. 
[20] Grenfell, M., \& Macaro, E. (2007). Language learner strategies: Claims and critiques. In A.D. Cohen, \& E. Macaro (Eds.), Language Learner strategies: 30 years of research and practice (pp. 9-28). Oxford University Press.

[21] Griffiths, C. (Ed.). (2008). Lessons from good language learners. Cambridge University Press.

[22] Hansen, J., \& Stansfield, C. (1981). The relationship of field dependent-independent cognitive styles to foreign language achievement. Language Learning, 31(2), 349-367. doi:10.1111/j.1467-1770.1981.tb01389.x

[23] Hatch, E. M., \& Lazaraton, A. (1991). The research manual: Design and statistics for applied linguistics. Newbury House Publishers.

[24] Krashen, S. D., Long, M. A., \& Scarcella, R. C. (1979). Age, rate and eventual attainment in second language acquisition. TESOL Quarterly, 573-582.

[25] Lightbown, P., \& Spada, N. (2013). How languages are learned. Oxford University Press.

[26] Macaro, E. (2006). Strategies for language learning and for language use: Revising the theoretical framework. The Modern Language Journal, 6, 320-337.

[27] Mclnerney, D. M., \& Van Etten, S. (Eds.). (2004). Big theories revisited. IAP.

[28] Naiman, N., Fröhlich, M., Stern, H. H., \& Todesco, A. (1975). The Good Language Learner: A Report. Ontario Institute for Studies in Education.

[29] Norton, B. \& Toohey, K. (2001). Changing perspectives on good language learners. TESOL Quarterly, 35(2), $307-322$.

[30] O'Malley, J. M. \& Chamot, A. U. (1990). Learning strategies in second language acquisition. Cambridge University Press.

[31] Oxford, R., \& Nyikos, M. (1989). Variables affecting choice of language learning strategies by university students. The Modern Language Journal, 73(3), 291- 300.

[32] Oxford, R. (1990). Language learning strategies. What every teacher should know. Newbury House.

[33] Reiss, M. A. (1981). Helping the unsuccessful language learner. Modern Language Journal, 121-128.

[34] Richards, J. C., \& Rodgers, T. (2001). Approaches and methods in language teaching (2nd Ed.). Cambridge University Press.

[35] Robinson, M.A. (1992). Introspective methodology in interlanguage pragmatics research. In G. Kasper (ed.), Pragmatics of Japanese as native and target language (Technical Report No. 3). University of Hawaii at Manoa, Second Language Teaching and Curriculum Center, 2782.

[36] Rogers, C. (1969). Freedom to learn: A view of what education might become. Charles Merill, 358.

[37] Rubin, J. (1975). What the 'good language learner' can teach us. TESOL Quarterly 9, 41-51.

[38] Rubin, J., \& Henze, R. (1981). The foreign language requirement: a suggestion to enhance its educational role in teacher training. TESOL Newsletter, 2 (81), 17, 19, 24.

[39] Rubin, J., \& Thompson, I. (1994). How to be a more successful language learner. Ryan, R.M., \& Deci, E.L. (2000). Intrinsic and extrinsic motivations: classic definitions and new directions. Contemporary Educational Psychology, 25, 54-67.

[40] Skehan, P. (1989). Individual Differences in Second Language Learning. Edward Arnold.

[41] Skehan, P. (1991). Individual differences in second language learning. Studies in Second Language Acquisition, 2, 275-298.

[42] Stern, H. H. (1975). What can we learn from the good language learner?. Canadian Modern Language Review, 31, $304-318$.

[43] Stern, H. H., Tarone, E. E., Stern, H. H., Yule, G., \& Stern, H. (1983). Fundamental concepts of language teaching: Historical and interdisciplinary perspectives on applied linguistic research. Oxford University Press.

[44] Ushioda, E. (2001). Language learning at university: exploring the role of motivational thinking. In Z. Dörnyei \& R. Schmidt (eds.), Motivation and second language acquisition. University of Hawai'i, 93-125.Vann, R.G. \& Abraham, R.J. (1990). Strategies of unsuccessful language learners. TESOL Quarterly, 24(2), 177-198.

[45] Volet, S. E., \& Järvelä, S. E. (2001). Motivation in learning contexts: Theoretical advances and methodological implications. Pergamon Press.

[46] Vygotsky, L.S. (1978). Mind in society: The development of higher psychological processes. MIT Press.

[47] Wahyudi, R (2014). What does good language learner (GLL) Say about foreign language learning? A story from an Indonesian learner. ALLS: Australian International Academic Centre, Australia.

[48] Wenden, A. L., \& Rubin, J. (1987). Learner strategies in language learning. Prentice-Hall.

[49] White, C. (2008). Language learning strategies in independent language learning: An overview. In S. Hurd, \& T. Lewis (Eds.), Language learning strategies in independent settings (pp.3-24). Multilingual Matters. 